\title{
IDÉIAS
}

\section{Parlamentarismo é mais democrático}

\author{
Pimenta da Veiga
}

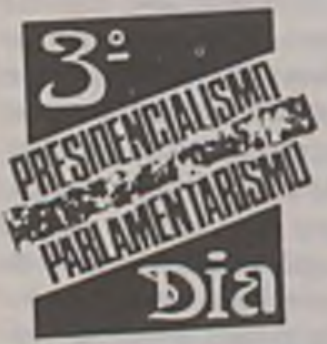

"Louvo a iniciativa do Ministro da Administração, que promove um debate sobre o sistema de governo, dando mostra de que compreende que qualquer que

seja o sistema adotado pela Assembléia Constituinte, especialmente se esse sistema for o parlamentarismo, só terá êxito se a administração pública estiver preparada para cumprir sua missão.

Depois de todas as idéias aqui expostas, não poderia ter a pretensão de aditar nenhuma idéia nova. $O$ que desejo, portanto, é apenas trazer algumas conclusões subjetivas, algumas contribuições pessoais, do entendimento que tenho sobre esta questão que foi, sem dúvida, uma das que mais contribuiram para a própria convocação da Assembléia Nacional Constituinte, e que é o tradicional debate brasileiro sobre o parlamentarismo e o presidencialismo.

Nós gostariamos de que o Brasil adotasse, para o seu próximo governo, o sistema parlamentarista. Entendemos que ele é uma forma mais moderna de dirigir a administração pública.

Ao ouvir com atenção os debates que foram aqui travados, as idéias que foram aqui expostas, devo confessar que considero como uma das mais impressionantes análises do sistema de governo americano a que nos fez, nesta manhã, o professor James Young, porque dele ouvi que o regime presidencialista americano está em mutação. Se nós analisarmos o sistema de governo dos paises de um modo geral, havere-

Pimenta da Veiga é Deputado Federal pelo PMDB de Minas Gerais. Debatedor no 2: Dia.

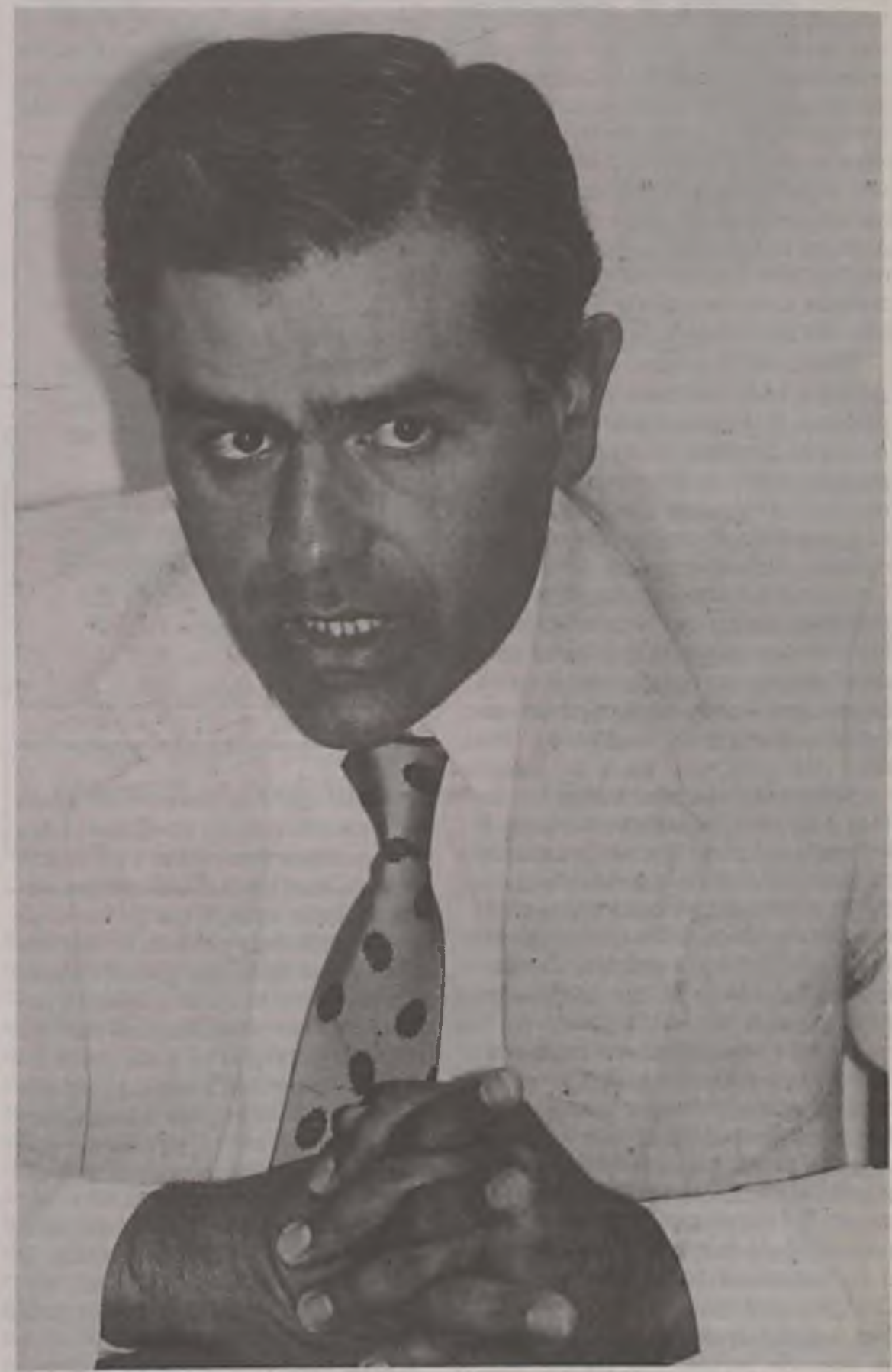


mos de verificar que os EUA são hoje, talvez, o único país importante de todo o mundo que ainda adota o sistema presidencialista. E ouvimos aqui que até mesmo este país está promovendo profundas alterações no seu sistema de governo.

Não é possivel administrar a complexidade dos negócios públicos através da decisão imperial de apenas uma pessoa. A administração pública deve ser participativa. Ouvi aqui, como síntese dos argumentos expostos pelos presidencialistas que aqui desfilaram suas idéias, que não devemos adotar o parlamentarismo porque os partidos brasileiros não são suficientemente estáveis, e que não temos também uma burocracia estável. Estes, eu me permito dizer, eu me atrevo a dizer, são os dois mais batidos argumentos dos presidencialistas e, no meu modo de entender, não são procedentes.

O sistema de governo ou a força dos partidos estão atrelados ao sistema de governo. Enquanto tivermos no Brasil o sistema presidencialista não teremos partidos políticos diferentes do que temos hoje e enquanto tivermos no Brasil o presidencialismo não teremos a burocracia estável que nós desejamos. Uma coisa é fruto da outra. Pretender primeiro corrigir um lamentável fisiologismo dos políticos brasileiros para depois implantar o parlamentarismo é querer, sem dúvida, negar o parlamentarismo permanentemente para o Brasil.

Acho que estas duas razōes nos levam à adoção do parlamentarismo. É indispensável para o fortalecimento dos partidos politicos que eles tenham um poder efetivo, e é necessário que a máquina burocrática do Estado estcja protegida da influência política, da deletéria influência política, para que possa alcançar a sua estabilidade.

Quando vejo defenderem parlamentarismo sem a dissolução do parlamento, fico verdadeiramente horrorizado. Não pode haver parlamentarismo sem esta sua marca fundamental, que é a possibilidade da dissolução do parlamento. E é exatamente aí que vem a responsabilidade do regime. Enquanto tem o Parlamento o poder de dissolver o Gabinete, terá que ter sempre o Executivo o poder de dissolver o Parlamento. Mas sou parlamentarista por uma razão fundamental: não quero continuar vendo este nosso país, que considero um país de condiçōes extraordinárias, exposto às cíclicas e constantes crises políticas que nos assolam. Não quero continuar vendo um país que tem todas as condições naturais de dar ao seu povo um conforto que ele ainda não tem exposto à miséria e a pobreza em que nós vivemos. Não quero que o Brasil continue vivendo as diferenças regionais e sociais em que vive, e para as quais só posso encontrar uma matriz política. Não é possivel continuar assim um país que tem a nossa extensão

Enquanto tivermos no
Brasil o sistema
presidencialista, não
teremos partidos políticos
diversos do que temos hoje
e, enquanto tivermos no
Brasil o sistema
presidencialista, não
teremos a burocracia
estável que nós desejamos.
Uma coisa é fruto da
outra.

territorial, que tem um povo da qualidade que tem o nosso povo, que já deu mostras de sua competência em muitas ocasiōes, aqui nesta cidade em que nós estamos neste instante, que foi construida pela força deste povo em apenas três anos, porque tinha uma grande liderança, porque contava com a unidade nacional para este propósito. Um pais que tem estas condiçōes só pode ainda estar convivendo com a miséria com que convive, com milhōes de menores desamparados vagando pelas ruas das grandes capitais brasileiras, por uma razão política. E não encontro outra razão que não seja esse presidencialismo, que não tem servido para gerenciar a administração pública brasileira.

Acho indispensável vivermos uma experiência parlamentarista.

Se não houvessem razões positivas para adotarmos o parlamentarismo, e vejo muitas destas razōes, algumas aqui expostas, eu seria parlamentarista pelas razões negativas do presidencialismo. Não posso aceitar que um povo tenha que se submeter à ação, volto a dizer, imperial, de um Presidente da República, por um prazo determinado e certo, ainda quando este Presidente da República esteja cometendo grandes desatinos. E não aceito argumentos de que o remédio para esta situação seria o golpe. Não aceito porque a história brasileira e a história dos demais países presidencialistas nos informam que o golpe nunca é adotado, até porque, desde o seu processo até a sua aplicação, o golpe não é nunca uma sanção política, é sempre uma sanção moral.

Quando se quer a substituição de um chefe de governo que está sendo inconveniente para o pais, o que se pretende é a adoção de uma sanção política que não é encontrada no presidencialismo. Para se iniciar um processo de impedimento, coloca-se no banco dos réus, perante o Senado Federal, o Presidente da República. A partir daquele momento, se o Congresso teve este poder, já não existe mais a autoridade do Presidente. Por isso ele não é aplicado. Não conheço casos, não só na história brasileira, mas mesmo em outros países, em que Presidente da República impedido ou mesmo o chefe do executivo impedido não tenha, naquele mesmo instante, esgotado sua vida pública.

Já o parlamentarismo tem, em sua essência, em seu bojo, a sanção política que se deseja para um mau governante. Aquele que, eventualmente, não estå conduzindo os interesses da nação como seria desejável, é afastado de suas funçōes por uma decisão política do Parlamento. E muitas vezes o PrimeiroMinistro que decai da confiança do parlamento, mais adiante, prosseguindo sua vida pública, chega até mesmo a voltar à mesma função, o que comprova que a sanção foi essencialmente política.

O que há de notável no parlamentarismo é exatamente esta faculdade que nos dá de conjurar as crises, de resolver as crises políticas que desgraçadamente, em nosso país, quando chegam a um determinado nível, nos conduzem necessariamente à rutura das instituiçōes democráticas. $\mathrm{O}$ que mais desejo 


\section{IDÉIAS}

na qualidade de constituinte, e de um constituinte que não está apoiando eventualmente o parlamentarismo, mas que tem isto como uma decisão refletida e arraigada, o que mais desejo é prevenir, é dotar o meu país de um sistema de governo, de uma forma de governo que seja impeditiva ou que, pelo menos, venha a dificultar a ocorrência dos golpes de Estado, que são verdadeiramente abomináveis, que produzem sempre um retrocesso que nos leva, que nos consome dezenas de anos para corrigir suas constantes, suas indestrutiveis quase mazelas políticas e administrativas. Para prevenir o Brasil da ocorrência desses abomináveis golpes de Estado é que tenho lutado pelo parlamentarismo, porque vejo que os golpes de estado têm uma história, eles têm um percurso que rotineiramente são cumpridos. Primeiro geram as dificuldades governamentais, primeiro criam a inquietação popular para aumentar a crise e, quando essa crise chega a um ponto $\mathrm{em}$ que a própria opinião pública diz que é insuportável a continuação daquele governo, então há a eclosão do golpe de Estado. Para remédio, para que isso não ocorra, o único remédio que temos é a substituição do regime do governo pela via democrática. Isto quer dizer, no regime parlamentarista, a simples reunião do Parlamento com a votação de uma moção de desconfiança.

Haveria um grande desestímulo para aqueles que rondam os quartéis, como foi mencionado pelo Senador Passarinho, querendo incitar os militares a um grande desestímulo para os próprios militares golpistas.

Se outra razão não houvesse, essa seria, para mim, suficientemente forte para sermos parlamentaristas. Mas o que vejo, concluindo, é que o parlamentarismo, ao dividir as responsabilidades, ao tornar mais cristalinas e transparentes as decisões de governo, é, sem dúvida, um sistema muito mais democrático.

Além do mais, o regime parlamentarista tem, ou nos exige, um pré-requisito indispensável, que é a adoção, como mencionou o Senador José Richa, do sistema de votação distrital. Não defendo o sistema distrital puro como defendeu o Senador Richa, mas acho que uma das fontes de perturbação da nossa vida democrática é este

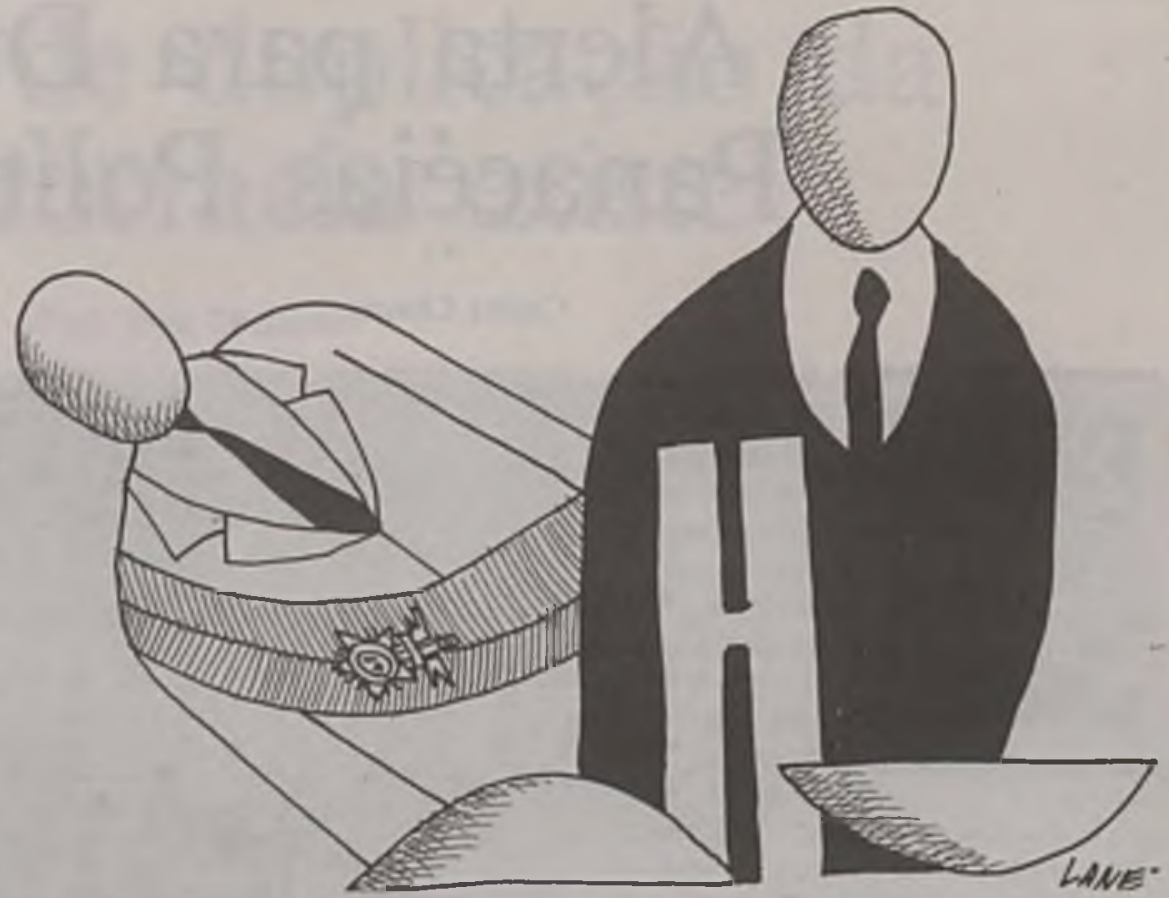

Posso até mesmo admitir que $10 \%$, que $20 \%$ de uma comunidade sejam sensiveis à influência do poder econômico, mas estou absolutamente convencido de que é impossivel a qualquer candidato conseguir influenciar a maioria absoluta dos votos de um distrito eleitoral. Por estas razões é que prefiro o voto distrital, mas na forma mista, para preservar o direito das minorias.

Não vejo por que reclamação das minorias políticas do país, se adotássemos para o Brasil um sistema de votação distrital mista, onde 20 ou $30 \%$ dos votos fossem decididos pelo sistema proporcional, a garantir, portanto, a estas minorias, sua insubstituivel participação no processo político nacional.

Por estas razōes é que tenho lutado corrupto sistema de voto proporcional, que estimula o uso da máquina pública e estimula também os investimentos econômicos nas campanhas eleitorais, que perturbam, definitivamente, o resultado das urnas. Num sistema de voto distrital, é muito mais fácil a percepção pelo eleitor do uso abusivo do poder econômico. A votação distrital é sempre majoritária. Dentro do distrito haverá sempre muito mais facilidade em denunciar o uso excessivo de recursos econômicos, e eu me recuso a admitir que seja possivel, através de favores materiais, conquistar-se a maioria, a maior parte dos votos de uma comunidade. pelo regime parlamentarista e estou certo até pela votação que já tivemos na bancada majoritária da Constituinte, que é a do PMDB, onde o sistema parlamentarista teve a aprovação de quase uma centena dos constituintes presentes, enquanto que o sistema presidencial teve apenas escassos nove votos. Eu estou certo de que o Brasil deverá viver uma experiência parlamentarista e eu confio, não será apenas uma experiência, mas será enfím o regime de governo que nós todos estamos buscando há tantos anos, há mais de 150 anos, e que, eu confio, será agora adotado pela Constituinte" 